\title{
EFFECT OF CERAMIC THICKNESS, TRANSLUCENCY AND CEMENT SHADE ON COLOR MASKING ABILITY OF PRESSABLE ZIRCONIA BASED LITHIUM SILICATE LAMINATE VENEER
}

\author{
Mohamed Fattouh Abdullah*
}

\begin{abstract}
Objective: This in-vitro study aimed to evaluate the effects of ceramic thicknesses and translucencies as well as resin cement shades on the masking ability of zirconia based lithium silicate discs (ZLC).

Materials and Methods: Eighty-four ceramic discs were manufactured from high translucent (HT) and translucent (T) ZLC ceramic. Discs were divided into three equal subgroups according to their thickness $(0.5,1,1.5 \mathrm{~mm})$. Background composite resin discs (shade C4D) were used to simulate the color of dark abutments. Ceramic discs were cemented to composite ones with either translucent or opaque resin cements. Color parameters were measured using a spectrophotometer and recorded by CIELab system, color difference between ceramic discs and cemented ceramic discs to composite were calculated as $\Delta \mathrm{E}$. All data were statistically analyzed using unpaired-t test, ANOVA test and Tukey HSD test. Statistical significance was set at $\mathrm{p}<0.05$.
\end{abstract}

Results: A statistically significant color difference $(\Delta \mathrm{E})$ was found between $(\mathrm{HT})$ and $(\mathrm{T})$ discs $(\mathrm{P}<0.05) . \Delta \mathrm{E}$ values of both translucencies were affected by ceramic thickness $(\mathrm{P}=0.000)$. Resin cement shade had no significant effect on $\Delta \mathrm{E}$ values when the thicknesses of ceramic veneer were $1.0 \mathrm{~mm}$ or $1.5 \mathrm{~mm}$ (P values=0.495 and 0.265 respectively). While the cement shades had a highly significant effect on $\Delta \mathrm{E}$ values when ceramic disc thickness was $0.5 \mathrm{~mm}(\mathrm{P}$ value $<0.0001)$.

Conclusion: As the veneer thickness increased, color change decreased significantly. Ceramic translucency and cement shade significantly influence the final color of pressable ZLC veneers only if the thickness is less than $1 \mathrm{~mm}$.

KEYWORDS: Color, Laminate veneers, Zirconia based lithium silicate, Resin cement, Ceramic thickness.

\footnotetext{
* Associate Professor, Fixed Prosthodontics Department, Faculty of Dentistry, Cairo University, Giza, Egypt.
} 


\section{INTRODUCTION}

Recent improvements in esthetic dentistry led to the development of innovative ceramic materials with better mechanical, physical and optical properties. ${ }^{1}$ Since the 2000s, lithium silicate and disilicate glass ceramics as well as yttria-stabilized tetragonal zirconia polycrystal (Y-TZP) were used in fixed prosthodontics. ${ }^{2}$ Recently, zirconia-reinforced lithium silicate glass ceramics (ZLS) was introduced to the dental market ${ }^{3}$. In ZLS restorations, $10 \%$ zirconium dioxide $\left(\mathrm{ZrO}_{2}\right)$ particles are homogeneously incorporated inside lithium-metasilicate $\left(\mathrm{Li}_{2} \mathrm{SiO}_{2}\right)$ glass ceramic matrix improving its biocompatibility, surface finish, mechanical and esthetic properties. $^{3-5}$

In 2017, Saavedra et al ${ }^{6}$ reported satisfactory success rates of anterior crowns fabricated from ZLS after a 2-years clinical study. In 2020, Rinke et al ${ }^{7}$ concluded a $99 \%$ survival rate after success of sixty-six partial coverage ZLS crowns out of sixty-nine, after 3 years of observation period. ZLS may be presented as machinable CAD blocks either in a partially crystallized form as Vita Suprinity (Vita Zahnfabrik, Bad Säckingen, Germany) or in a fully crystallized state as Celtra Duo (Dentsply Sirona co., USA). ${ }^{8}$ In 2019, ZLC was presented as pressable pellets (Vita Ambria, Vita Zahnfabrik, Bad Säckingen, Germany), Vita Ambria is used for fabrication of inlays, onlays, partial veneer crowns, full veneer crowns, three- units bridges up to the second premolars and laminate veneers. ${ }^{9}$

In general, ceramic laminate veneers are preferable to resin laminates, as the latter's durability is questionable due to wear, discoloration and marginal fracture. ${ }^{10}$ Ceramic laminate veneers are bonded to the prepared and unprepared teeth with composite resin cement where the laminate's thickness varies from 0.5 to $1.5 \mathrm{~mm} .{ }^{11}$ Moreover, 0.3 $\mathrm{mm}$. thick prep-less anterior laminates are also possible. ${ }^{12}$ Shade matching of laminate veneer with the neighboring teeth and masking the original color of the abutment is a complex challenging clinical step. Final shade of a laminate veneer is influenced by many ceramics-related factors such as (ceramic brand and batches ${ }^{13}$, ceramic translucency and opalescence ${ }^{14,15}$,ceramic thickness and shade, condensation technique and number of firing cycles. ${ }^{16,17}$ In addition, cement shade and the color of underlying abutment are important factors. ${ }^{15,18,19}$ Translucent and highly translucent Vita Ambria ZLC are used in the construction of esthetically anterior laminate veneers, however their translucencies may affect the masking ability which means that discoloration may be noticeable through the ceramic.$^{20,21}$ When laminate veneer is thin, numerous shades 22,23 and brightness levels ${ }^{24,25}$ of resin cements may influence the color. Thus, optical properties of the composite resin cement decide the final color of veneers..$^{22,26}$.

Shade of the restoration can be determined either visually or instrumentally. Instrumental shade matching with a device as spectrophotometer can quantify color parameters (L, a, and b values) allowing precise and successful communication between prosthodontists and dental technicians ${ }^{27}$. The quantity of perceptible color changes in each specimen is evaluated using the Commission Internationale d'Eclairage (CIE) L,a,b measurements, The CIE Lab system was established based on the primary colors ${ }^{28}$ to exclude inherent variations in color perception among different evaluators. ${ }^{15}$

The objective of this study was to determine the effect of different ceramic thicknesses $(0.5 \mathrm{~mm}$, $1 \mathrm{~mm}$ and $1.5 \mathrm{~mm}$ ) fabricated from two Vita Ambria translucencies (Translucent, High translucent) and cemented on a chromatic background by two resin cement shades (translucent and opaque) on the masking ability and final color of laminate veneers. The null hypothesis was that different ceramic translucencies, ceramic thicknesses and resin cement shades would have no significant effect on the final color of laminate veneers. 


\section{MATERIALS AND METHODS}

Eighty-four ceramic discs (12 $\mathrm{mm}$ in diameter) were fabricated using ZLC pressable ceramic material (Vita Ambria, Vita Zahnfabrik, Bad Säckingen, Germany) from low translucency and translucent (T) ingots (A1 shade). The sample size was calculated using $\mathrm{G}^{*}$ Power analysis program (v3.1.9; Heinrich-Heine-Universität Düsseldorf, Germany). According to previous studies ${ }^{3,11,19}, 42$ specimens per group representing $80 \%$ power, considering $\alpha$ equal to $5 \%$.

Samples were divided into two equal groups: group I: High Translucent (HT) discs $(n=42)$ and group II: Translucent $(\mathrm{T})$ discs $(\mathrm{n}=42)$. Samples were subdivided into three equal subgroups $(n=14)$ according to ceramic disc thickness: Subgroup A: $0.5 \mathrm{~mm}$, Subgroup B: $1 \mathrm{~mm}$, Subgroup C: $1.5 \mathrm{~mm}$. Then samples were further equaly subdivided into two divisions ( $n=7)$ according to the shade of resin cement used; Division 1: samples were cemented with translucent resin cement. Division 2: samples were cemented with opaque resin cement. Sample grouping is shown in Table (1). Materials used in this study with their commercial name, specifications, compositions, and manufacturer are presented in Table (2).

TABLE (1) Sample Grouping

\begin{tabular}{|c|c|c|c|c|c|c|c|c|c|c|c|}
\hline \multicolumn{6}{|c|}{$\begin{array}{c}\text { HT Discs } \\
\text { (42 samples) }\end{array}$} & \multicolumn{6}{|c|}{$\begin{array}{c}\text { T Discs } \\
\text { (42 samples) }\end{array}$} \\
\hline \multicolumn{2}{|c|}{$\begin{array}{c}0.5 \mathrm{~mm} \\
(14 \text { samples })\end{array}$} & \multicolumn{2}{|c|}{$\begin{array}{c}1 \mathrm{~mm} \\
\text { (14samples) }\end{array}$} & \multicolumn{2}{|c|}{$\begin{array}{c}1.5 \mathrm{~mm} \\
\text { (14samples) }\end{array}$} & \multicolumn{2}{|c|}{$\begin{array}{c}0.5 \mathrm{~mm} \\
\text { (14samples) }\end{array}$} & \multicolumn{2}{|c|}{$\begin{array}{c}1 \mathrm{~mm} \\
(14 \text { samples }) \\
\end{array}$} & \multicolumn{2}{|c|}{$\begin{array}{c}1.5 \mathrm{~mm} \\
\text { (14samples) }\end{array}$} \\
\hline 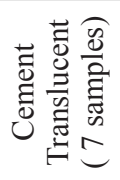 & 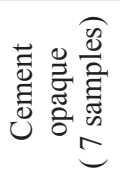 & 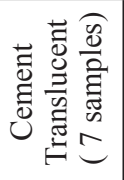 & 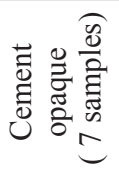 & 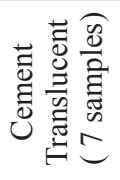 & 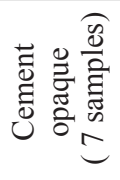 & 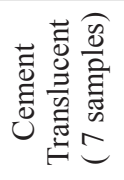 & 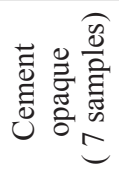 & 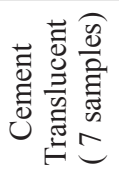 & 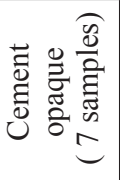 & 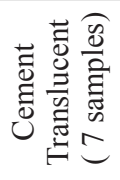 & 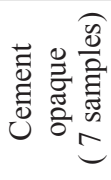 \\
\hline
\end{tabular}

TABLE (2) Materials used in this study

\begin{tabular}{|c|c|c|c|c|}
\hline Material & Type of material & Shade & composition & Manufacturer \\
\hline Vita Ambria & $\begin{array}{l}\text { Pressable } \\
\text { Zirconia } \\
\text { reinforced lithium } \\
\text { silicate ceramic }\end{array}$ & $\begin{array}{l}\text {-Highly } \\
\text { translucent } \\
\text {-Translucent }\end{array}$ & $\begin{array}{c}\text { Components Wt. } \%: \\
\mathrm{SiO}_{2} 58-66 \%, \mathrm{Li}_{2} \mathrm{O}_{12}-16 \%, \mathrm{ZrO}_{2} 8-12 \%, \mathrm{Al}_{2} \mathrm{O}_{3} \\
1-4 \%, \mathrm{P}_{2} \mathrm{O}_{5} 2-6 \%, \mathrm{~K}_{2} \mathrm{O} 1-4 \%, \mathrm{~B}_{2} \mathrm{O}_{3} 1-4 \% \\
\mathrm{CeO}_{2} 0-4 \%, \mathrm{~Tb}_{4} \mathrm{O}_{7} 1-4 \%, \mathrm{~V}_{2} \mathrm{O}_{5}<1 \%, \mathrm{Er}_{2} \mathrm{O}_{3}<1 \\
\%, \mathrm{Pr}_{6} \mathrm{O}_{11}<1 \%\end{array}$ & $\begin{array}{l}\text { Vita Zahnfabrik, } \\
\text { Bad Säckingen, } \\
\text { Germany }\end{array}$ \\
\hline $\begin{array}{l}\text { Filtek Z350 } \\
\text { XT }\end{array}$ & $\begin{array}{l}\text { visible light- } \\
\text { activated } \\
\text { composite }\end{array}$ & $\begin{array}{l}\text { C4D } \\
\text { (Dentine } \\
\text { body) }\end{array}$ & $\begin{array}{l}20 \mathrm{~nm} \text { silica filler, non- agglomerated/non-aggregated } \\
4 \text { to } 11 \mathrm{~nm} \text { zirconia filler, and aggregated zirconia/ } \\
\text { silica cluster filler (comprised of } 20 \mathrm{~nm} \text { silica and } 4 \text { to } \\
11 \mathrm{~nm} \text { zirconia particles). }\end{array}$ & $\begin{array}{c}\text { 3M, ESPE, St } \\
\text { Paul, MN, USA }\end{array}$ \\
\hline $\begin{array}{l}\text { RelyX Veneer } \\
\text { cement }\end{array}$ & $\begin{array}{l}\text { Light-cure, } \\
\text { methacrylate } \\
\text { resin-based luting } \\
\text { material. }\end{array}$ & $\begin{array}{l}\text {-Translucent } \\
\text { - Opaque }\end{array}$ & $\begin{array}{l}\text { bisphenol-A-diglycidylether dimethacrylate (BisG- } \\
\text { MA) and triethylene glycol dimethacrylate (TEG- } \\
\text { DMA) polymer. } \\
\text { Zirconia/silica and fumed silica fillers are used to impart } \\
\text { radiopacity, wear resistance and physical strength. } \\
\text { The filler loading is approximately } 66 \% \text { by weight. } \\
\text { The average particle size for thefiller is approximately } \\
0.6 \mathrm{~mm} \text {. }\end{array}$ & $\begin{array}{c}\text { 3M, ESPE, St } \\
\text { Paul, MN, USA }\end{array}$ \\
\hline $\begin{array}{l}\text { RelyX Ceramic } \\
\text { Primer }\end{array}$ & Ceramic primer & & $\begin{array}{c}\text { prehydrolyzed silane-coupling agent, alcohol and } \\
\text { water. }\end{array}$ & $\begin{array}{l}\text { 3M, ESPE, St } \\
\text { Paul, MN, USA }\end{array}$ \\
\hline
\end{tabular}




\section{Fabrication of Pressable ZLC discs}

Three custom-made Teflon molds were constructed with $12-\mathrm{mm}$. diameter to standardize the diameter of disc-shaped wax patterns but with different heights. The first mold was $0.5 \mathrm{~mm}$ high, the second was $1 \mathrm{~mm}$. While the third was $1.5 \mathrm{~mm}$ high. The 42-wax patterns of group I were sprued and weighted to calculate the needed quantity of Ambria HT pellets. Investing was done in a silicone ring using phosphate bonded investment powder and liquid (Vita Ambria Invest,Vita Zahnfabrik, Bad Säckingen, Germany) with the Vita Ambria muffle system. After setting of the investment, the investment ring was removed from the muffle and separated from the ring. Investment ring was preheated at $850^{\circ} \mathrm{C}$ for 75 minutes. Pressing was done using HT pellets (shade A1) with a disposable press plunger (Vita Ambria plunger, Vita Zahnfabrik, Bad Säckingen, Germany) in combipress unit (Vita Vacumat 6000, Vita Zahnfabrik, Bad Säckingen, Germany). After pressing the ring was removed from the furnace and allowed to cool then divestment was done. The same procedures were repeated using translucent pellets for group II (T).All samples were inspected for any imperfections. The thickness of all specimens were then checked with a micrometer (Renfert Calipretto S, Renfert GmbH, Hilzingen, Germany) to be sure that the tested thicknesses were $(0.5,1$, or $1.5 \mathrm{~mm})$. Finishing and polishing was done using Vita Suprinity polishing set (Vita Zahnfabrik, Bad Säckingen, Germany). The surfaces of all samples were cleaned in an ultrasonic bath with distilled water for 10 minutes and then dried using compressed air. The down surfaces of the discs that would face the cement were etched with Vita ceramic etch gel (Vita Zahnfabrik, Bad Säckingen, Germany) for 20 seconds then rinsed followed by application of ceramic primer (RelyX Ceramic Primer,3M ESPE, St Paul, MN, USA). Finally, surface glaze were applied to the upper surfaces of the discs that would face the spectrophotometer (Vita Akzent plus stain, Vita Zahnfabrik, Bad Säckingen, Germany).

\section{Fabrication of composite resin discs and cemen- tation procedures}

To simulate the shade of a dark abutment, a nanohybrid composite discs of shade C4 Dentine (Filtek Z250, 3M ESPE, St Paul, MN, USA) were fabricated .They were made using a silicone mold made of Putty consistency PVS (Affinis, Coltene co., Switzerland), with the following dimensions 12 $\mathrm{mm}$ in diameter and $5 \mathrm{~mm}$ in thickness. The treated Vita Ambria specimens were cemented to composite resin discs. Light-cured resin cement (RelyX Veneer cement system, 3M ESPE, St Paul, MN, USA) with either translucent (Cem TR) or opaque (Cement Op) shades were applied and cured for 30 seconds.

To ensure that cement had standard thickness $(0.1 \mathrm{~mm})$ in all samples, a specially designed ring stopper $6 \mathrm{~mm}$ in thickness was fabricated. ${ }^{29}$ Composite disc was placed inside the stopper, then the cement was applied followed by application of Vita Ambria samples with the treated surface facing the cement followed by applying a $750 \mathrm{gm}$ load for 10 seconds. ${ }^{3}$ All Samples were numbered from 1 to 7 for each division and then divided randomly by online site (www.random.org) at allocation ratio 1:1 and sealed in closed envelopes to prevent any bias.

\section{Shade measurements}

All measurements were performed by a welltrained clinician (M.F.) to evaluate the shade. Samples' shade were measured using spectrophotometer (Vita Easyshade Advance, Vita Zahnfabrik, Bad Säckingen, Germany). Before measurements, Vita Easyshade Advance was calibrated using its tile according to the manufacturer's instructions, Easyshade screen displayed the $\mathrm{L}^{*} \mathrm{a}^{*} \mathrm{~b}^{*}$ coordinates for the measured shade, CIELab values were recorded for the ceramic discs thicknesses and these measurements were kept as base readings. Then, Vita Easyshade measured each ceramic disc complex (Vita Ambria disc + cement +composite disc) three times; disc's color was determined by calculating the average of the three readings (Fig.1). All recorded 
values in CIELab coordinates of ceramic discs and ceramic disc complex were transferred to a personal computer (Dell latitude E5540, Dell co., USA). The CIELab measurements can evaluate the amount of perceptible color variations in each sample. The total color difference $(\Delta \mathrm{E})$ between the two readings was calculated with the following equation ${ }^{30}$ :

$$
\Delta \mathrm{E}=\left[(\Delta L)^{2}+\left[(\Delta a)^{2}+\left[(\Delta b)^{2}\right]^{1 / 2}\right.\right.
$$

The L coordinate is the amount of lightness-darkness in the samples (from $0=$ black to $100=$ perfect white). The a coordinate is a degree of the chroma along the red-green axis. A positive a: indicates the redness of the sample, while a negative a: indicates its greenness. The b coordinate is the extent of chroma along the yellow-blue axis, a positive $b$ : denotes the amount of yellowness; a negative $b$ : denotes the amount of blueness of the sample. $\Delta \mathrm{L}, \Delta \mathrm{a}$, and $\Delta \mathrm{b}$ signify dissimilarities between two colors in CIE color-space parameters. ${ }^{30}$ It is worth to mention that if the value of $\Delta \mathrm{E}>3$, no masking will be found and change in color will be noticed clinically. ${ }^{31}$

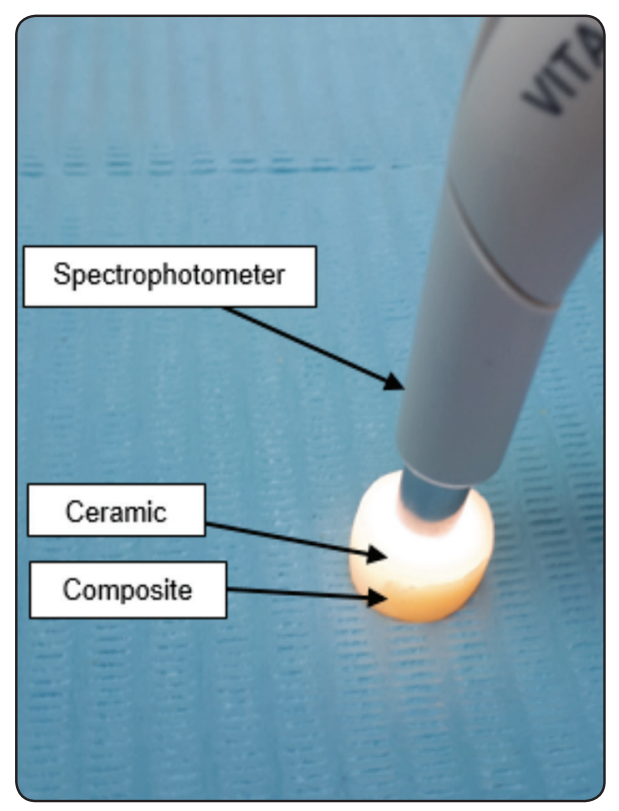

Fig. (1) Color measurement for ceramic disc complex using spectrophotometer.

\section{Statistical Analysis}

All color difference measurements [mean and standard deviation (SD) of $\Delta \mathrm{E}]$ were collected and tabulated. Data were examined with ShapiroWilk test for normality and found to be normally distributed among all groups. Comparison of all groups were analyzed using independent t-test, oneway Analysis Of Variance (ANOVA) test, followed by Tukey HSD test to determine any statistical significant difference between the individual groups. For statistical analysis, Statistical Package for the Social Sciences (SPSS version 22.0, IBM Corporation, New York, USA) was used. P-value $<0.05$ was considered to be statistically significant.

\section{RESULTS}

Mean and standard deviation (SD) of $\Delta \mathrm{E}$ of different tested groups and interactions between different tested variables are presented in tables (3, 4,5) (Fig.2). Statistical analysis using unpaired-t test showed that there was a highly statistically significant difference of $\Delta \mathrm{E}$ values between the two main groups of high translucent Ambria and translucent Ambria discs $(\mathrm{P}<0.0001)$. The highest mean $\Delta \mathrm{E}$ values were recorded for High Translucent Ambria with $0.5 \mathrm{~mm}$ thickness and cemented by translucent cement $(\Delta \mathrm{E}=5.2 \pm 0.29)$, while, the lowest mean $\Delta \mathrm{E}$ values was recorded by Translucent Ambria with $1.5 \mathrm{~mm}$ thickness and cemented by opaque resin cement $(\Delta \mathrm{E}=1.93 \pm 0.38)$. However, $\Delta \mathrm{E}$ differences between groups were highly significant only when the thickness of the veneer was $0.5 \mathrm{~mm}$. As the thickness of the veneer increased to 1 and $1.5 \mathrm{~mm}$, these differences became statistically insignificant. All $\Delta \mathrm{E}$ values were less than 3, except for High translucent group with $0.5 \mathrm{~mm}$ thickness cemented by translucent or opaque cements and Translucent group with $0.5 \mathrm{~mm}$ cemented with translucent cements; $\Delta \mathrm{E}$ values were $(5.2 \pm 0.7,4.1 \pm 0.64$ and $3.65 \pm 0.57$ ) respectively (Fig.2)

ANOVA test showed no statistically significant color differences between (high translucent $1 \mathrm{~mm}$ 
thickness samples cemented with translucent cement) and (translucent samples $0.5 \mathrm{~mm}$ in thickness cemented with opaque cement) and between High translucent discs $1 \mathrm{~mm}$ in thickness cemented with opaque cement and translucent ones with similar 1 thicknesses cemented with opaque cement. Statistical comparison by Tukey's HSD multiple comparison to analyze Interactions between different groups showed that both cement shades (translucent, opaque) had no significant effect on $\Delta E$ values when the thicknesses of ceramic veneer were $1.0 \mathrm{~mm}$ or $1.5 \mathrm{~mm}$ ( $P$ values $=0.495$ and 0.265 respectively). While the resin cement shades had a highly significant effect on $\Delta \mathrm{E}$ values when disc thickness was $0.5 \mathrm{~mm}(P$ value $<0.0001)$.

For all subgroups, the mean $\Delta \mathrm{E}$ values decreased significantly $(\mathrm{P}<0.0001)$ as the veneer thickness increased (table 4).

TABLE (3) Mean and standard deviation of $\Delta E$ values of different thicknesses of (T, HT) Vita Ambria laminate veneer with translucent (Cement TR) and opaque (Cement Op) cements

\begin{tabular}{|c|c|c|c|c|c|}
\hline & \multicolumn{2}{|c|}{ High Translucency(HT) } & \multicolumn{2}{|c|}{ Translucency(T) } & \multirow[t]{2}{*}{$P$-value } \\
\hline & Cement TR & Cement OP & Cement TR & Cement OP & \\
\hline & Mean \pm SD & Mean \pm SD & Mean \pm SD & Mean \pm SD & \\
\hline $0.5 \mathrm{~mm}$ & $5.2 \pm 0.29^{\mathrm{a}}$ & $4.1 \pm 0.19^{\mathrm{a}}$ & $3.65 \pm 1^{\mathrm{a}}$ & $2.53 \pm 0.37^{\mathrm{a}}$ & $0.0001 *$ \\
\hline $1 \mathrm{~mm}$ & $2.53 \pm 0.44^{\mathrm{b}}$ & $2.29 \pm 0.19^{b}$ & $2.3 \pm 0.44^{\mathrm{b}}$ & $2.28 \pm 0.26^{\mathrm{a}, \mathrm{b}}$ & 0.495 \\
\hline $1.5 \mathrm{~mm}$ & $2.3 \pm 0.33^{\mathrm{b}}$ & $2.12 \pm 0.34^{\mathrm{b}}$ & $2.11 \pm 0.28^{b}$ & $1.93 \pm 0.38^{b}$ & 0.265 \\
\hline$P$-value & $0.000 *$ & $0.000 *$ & $0.000^{*}$ & $0.000 *$ & \\
\hline
\end{tabular}

* Similar superscript letters indicate statistically insignificant differences between the different thicknesses in each subgroup.

* Different superscript letters indicate statistically significant differences between the different thicknesses in each subgroup.

TABLE (4) Pairwise comparison between the groups regarding ceramic thickness by Tukey's test

\begin{tabular}{|c|c|c|c|c|c|c|}
\hline & \multicolumn{2}{|c|}{$0.5 \mathrm{~mm}$} & \multicolumn{2}{|c|}{$1 \mathrm{~mm}$} & \multicolumn{2}{|c|}{$1.5 \mathrm{~mm}$} \\
\hline & Mean range & $P$-value & Mean range & $P$-value & Mean range & $P$-value \\
\hline TCT vs HTCT & 1.6 & $0.00 *$ & 0.23 & 0.618 & 0.37 & 0.197 \\
\hline TCT vs HTC0 & 1.3 & $0.004 *$ & 0.01 & 1 & 0.19 & 0.72 \\
\hline TCT vs TCO & 1.1 & $0.005^{*}$ & 0.02 & 1 & 0.01 & 1 \\
\hline TCO vs HTCT & 2.7 & $0.00 *$ & 0.25 & 0.553 & 0.19 & 0.72 \\
\hline TCO vs HTCO & 1.6 & $0.00 *$ & 0.01 & 1 & 0.01 & 1 \\
\hline HTCT vs HTCO & 1.1 & $0.006 *$ & 0.24 & 0.585 & 0.18 & 0.751 \\
\hline
\end{tabular}

* Indicates significant difference between groups $(P<0.05)$ 
TABLE (4) Pairwise comparison between the groups regarding cement shade by Tukey's test

\begin{tabular}{|c|c|c|c|c|c|c|c|c|}
\hline & \multicolumn{4}{|c|}{ High Translucency } & \multicolumn{4}{c|}{ Translucency } \\
\cline { 2 - 10 } & \multicolumn{2}{|c|}{ Cement TR } & \multicolumn{2}{c|}{ Cement OP } & \multicolumn{2}{c|}{ Cement TR } & \multicolumn{2}{c|}{ Cement OP } \\
\cline { 2 - 10 } & Mean range & $P$-value & Mean range & $P$-value & Mean range & $P$-value & Mean range & $P$-value \\
\hline $\mathbf{0 . 5 m m}$ vs 1mm & 2.67 & $0.00 *$ & 1.81 & $0.00 *$ & 1.35 & $0.004 *$ & 0.25 & 0.303 \\
\hline $\mathbf{0 . 5 m m}$ vs $\mathbf{1 . 5 m m}$ & 2.9 & $0.00 *$ & 1.98 & $0.00 *$ & 1.72 & $0.00 *$ & 0.42 & $0.049 *$ \\
\hline $\mathbf{1 m m}$ vs $\mathbf{1 . 5 m m}$ & 0.23 & 0.192 & 0.17 & 0.433 & 0.37 & 0.562 & 0.17 & 0.564 \\
\hline
\end{tabular}

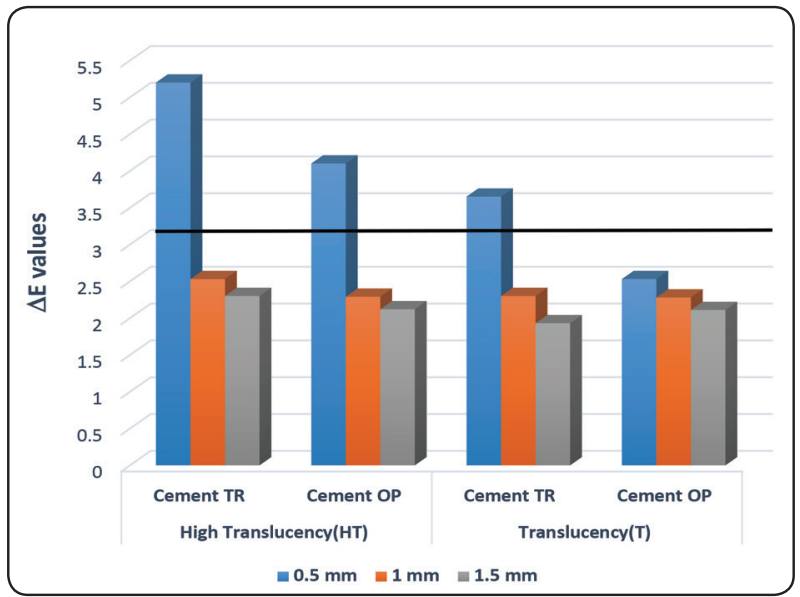

Fig. (2) Mean $\Delta E$ values of different thicknesses of Vita Ambria HT, T discs cemented with Translucent and opaque cements

\section{DISCUSSION}

Results of the current study revealed that increasing the veneer thickness significantly decreased color change and that ceramic translucency and cement shade had an influential effect on color only in veneers less than $1 \mathrm{~mm}$ in thickness, with translucent ceramics and opaque cements showing superior color masking abilities. Hence, the null hypothesis could be partially rejected.

The desire for enhanced esthetics has resulted in increased acceptance and extensive use of ceramic fixed restorations. ${ }^{32,33}$ ZLC has a uniform glassy matrix which contains crystalline elements of elongated grains of lithium orthophosphates and lithium metasilicates. Increasing its strength was done by incorporation of zirconia tetragonal fillers ${ }^{34}$.
The optical characteristic of ZLC restorations are determined by series of factors including: ceramic layer thickness, cement shade and tooth structure shade..$^{11}$ Teeth shade may be changed due to intrinsic or extrinsic stains; intrinsic stains may be due aging, intra-pulpal hemorrhage, pulp necrosis, tetracycline or certain diseases while extrinsic tooth stains may resulted from colored food or beverages as tea, coffee and tobacco. ${ }^{35}$

Teeth discolorations may be treated either by bleaching or laminate veneers. Teeth reductions for laminate veneers are very conservative remaining within the enamel tissues allowing better bond strength than dentine. ${ }^{36}$ Preparation in enamel necessitates minimum ceramic thickness and accepted translucency. Selection of a translucent laminate veneer to produce an ideal shade match is a critical factor especially over darkened abutment as it may influence the final color of the restorations. ${ }^{37,38}$ that is why this study was designed to investigate the effect of laminate's thickness, cement shade and underlying structure darkness on postcementation color of HT, T Vita Ambria discs. Final color changes of Vita Ambria specimens (HT,T) with three different thicknesses $(0.5 \mathrm{~mm}, 1 \mathrm{~mm}$, $1.5 \mathrm{~mm}$ ) cemented either with translucent or opaque composite resin cements were observed. In this study, laminate veneers are not a single ceramic layer, but rather involve a whole component of ceramic layer, cement shade and a background mimicking the tooth shade. The selected shade for the Vita Ambria pellets was A1 as it is the most commonly 
used shade for all-ceramic restorations in addition, it was used in many similar studies ${ }^{39-45}$. The selection of using a chromatic background was planned to simulate a classical clinical condition in which the abutment was dark; $\mathrm{C} 4$ shade was used, as it is one of the darker shades. The thickness of cement was chosen to be $0.1 \mathrm{~mm}$ to imitate clinical situations allowing better stress distribution at ceramic resin interface ${ }^{29,46}$. Vita Easyshade spectrophotometer was used to measure all samples as recommended by previous studies $3,27,31$, it is simple, easy and accurate. Dozić et a ${ }^{47}$ reported that Vita Easyshade was the most reliable appliance of shade matching in both in vivo and in vitro situations. CIELab system was used to record color changes in previous studies, ${ }^{29,31,36,38} \Delta \mathrm{E}$ values was an indicator if this color change would be detected clinically or not.

As mentioned earlier, the results of the present study showed that color difference $(\Delta \mathrm{E})$ of high translucent (HT) discs are higher than translucent (T) ones. Usually when light passes through a translucent material, intensity of light is reduced and light rays are scattered by small-sized particles as filler and internal voids. The amount of incident light that appears as diffuse transmission is important for color observation and appearance of dental ceramics. ${ }^{48,49}$

The higher $\Delta \mathrm{E}$ of Translucent discs may be attributed to the fact that Vita Ambria translucent pellets have more lithium disilicate crystals than high translucent pellets. Crystals decrease the inner scattering of light as it passes through the disc. This means that when the background has a darker color or the abutment is greatly discolored, the use of high translucency pressable ZLC may lead to limited success ${ }^{43,50-52}$. Pires et al ${ }^{45}$ reported similar results after comparing low opacity ceramic with the high opacity one and concluded that the latter showed lower color difference values. Al Hamad et al ${ }^{53}$ concluded that the color of the background affected the final color of lithium disilicate ceramic restorations and recommended using low translucency or opaque materials to hide the backgrounds darkness. In addition, Skyllouriotis et al ${ }^{54}$ reported that low translucency lithium disilicate ceramic crowns were better at masking dark backgrounds than high translucency lithium disilicate ceramic crowns. Hence, prosthodontists should think about decreasing translucency to mask the tooth color. It is worth mentioning however that most of the recorded color difference values were under the threshold of 3 which means that they were clinically acceptable.

To date, little data is known about properties of pressable ZLC due to limited available studies. Nonetheless, it is known that increasing ceramic thickness will increase its opacity $37,51,55$. When the thickness is increased, the diffused reflection influences of the background abutment is reduced, and majority of diffused reflection happens in the laminate veneer. The lowest color change values were recorded for the $1.5 \mathrm{~mm}$ thickness in all studied groups. Ceramics with either thickness of 1 and $1.5 \mathrm{~mm}$. had non-significant differences between their groups meaning that $1 \mathrm{~mm}$. thick veneer preparation is enough to mask the underlying color of dark abutments. Ge et al ${ }^{56}$ found that using gold shaded posts and cores did not affect the color of $1.5 \mathrm{~mm}$ thick Empress 2 crowns, and that the color difference was under the patients' normal perception level $(\Delta \mathrm{E}=1.8)$. Many studies correlate increasing ceramic thickness with better color results ${ }^{18,41,43,44,50,51}$ hence support the findings of the current study.

It was concluded that the type of polymerization could affect the color of the restoration; light cured resin cements are preferable in cementation of translucent and thin ceramic restorations because they have superior optical properties and color stability than dual cured cements..$^{57}$. In this study, light cured, translucent and opaque resin cements were used to exclude the possibility of color change. As shown in table 2, RelyX veneer cement does not contain camphorquinone which lead to a yellowish shade after light polymerization. ${ }^{58}$ Nor amine compound which 
causes discolorations as a result of oxidation reaction during its auto-polymerization. ${ }^{59}$ For all veneer thicknesses, opaque resin cement recorded lower color change values than the translucent cement in both translucent and high translucent ceramic groups. However, this superiority was significant only with the $0.5 \mathrm{~mm}$ veneer thickness. It seems that using opaque resin cements would be beneficial to mask dark or discolored abutments if laminate veneer thickness was $0.5 \mathrm{~mm}$ and will have no influential effect if the thickness increased to 1 or 1.5 $\mathrm{mm}$. Similar results were reported by Czigola et al ${ }^{60}$ who studied the effects of dark backgrounds and cement shades on the final color of lithium disilicate crowns and found that opaque shade cements and low translucency ceramic crowns might be beneficial in masking dark abutments. Similarly, results of many studies showed that the influence of resin cement shade on the final color is less considerable than other factors when the ceramic thickness was from 1.0 to $2.0 \mathrm{~mm} .{ }^{51,61}$

\section{Study limitations}

This study was carried under in vitro conditions without aging procedures. Only one shade (A1) was used, and all tested materials were from two manufacturers (VITA, 3M) only. Further studies should be conducted considering more thicknesses of ceramics, various shades from different manufacturers, as well as more resin cement types, thicknesses and shades.

\section{CONCLUSIONS}

Within the limitations of the present study, the following conclusions were drawn:

- Increasing veneer thickness from 0.5 to 1 to $1.5 \mathrm{~mm}$ significantly decreased color change in pressable ZLC veneers.

- Ceramic translucency and cement shade significantly influence the final color of pressable ZLC veneers only if the thickness is less than $1 \mathrm{~mm}$, hence laminate veneers with at least $1 \mathrm{~mm}$. thickness can mask the color of even dark abutments regardless of ceramic translucency and cement shade.

\section{Clinical Significance}

To mask the color of discolored abutments, it is recommended to use translucent pressable ZLC veneers with opaque resin cements if the veneer thickness is less than $1 \mathrm{~mm}$. However, if the veneer thickness is $1 \mathrm{~mm}$ or more, using high translucency veneers and translucent resin cements would still be clinically acceptable.

\section{Conflict of interest}

No conflicts of interest and no funding was received for the research that could have influenced its results.

\section{REFERENCES}

1. Alves LMM, Contreras LPC, Campos TMB, Bottino MA, Valandro LF, Melo RM. In vitro wear of a zirconiumreinforced lithium silicate ceramic against different restorative materials. J Mech Behav Biomed Mater. 2019 Dec;100:103403.

2. Alao A.-R, Fabrication and Characterization of Lithium Metasilicate/disilicate Glass Ceramics and Yttria Tetragonal Zirconia Polycrystals for Dental Restorations, PhD Thesis, James Cook University, Australia, 2016.

3. Yildirim B, Recen D, Tekeli Simsek A. Effect of cement color and tooth-shaded background on the final color of lithium disilicate and zirconia-reinforced lithium silicate ceramics: An in vitro study. J Esthet Restor Dent. 2021 Mar;33(2):380-386.

4. Fu L, Engqvist H, Xia W. Glass-Ceramics in Dentistry: A Review. Materials (Basel). 2020 Feb 26; 13(5):1049.

5. Zhang Y. Making yttria-stabilized tetragonal zirconia translucent. Dent Mater. 2014 Oct; 30(10):1195-203.

6. Saavedra GSFA, Rodrigues FP, Bottino MA. ZirconiaReinforced Lithium Silicate Ceramic - A 2-Year Followup of a Clinical Experience with Anterior Crowns. Eur J Prosthodont Restor Dent. 2017 Mar; 25(1):57 63.

7. Rinke S, Pfitzenreuter T, Leha A, Roediger M, Ziebolz D. Clinical evaluation of chairside-fabricated partial crowns composed of zirconia-reinforced lithium silicate ceramics: 
3 -year results of a prospective practice-based study. J Esthet Restor Dent. 2020 Mar; 32(2):226-235.

8. Elsaka SE, Elnaghy AM. Mechanical properties of zirconia reinforced lithium silicate glass-ceramic. Dent Mater. 2016 Jul;32(7):908-14.

9. VITA AMBRIA. Press solution. VITA AMBRIA Brochure No.10610 (Version 002).Available at: https://www.vitazahnfabrik.com/en/VITA-AMBRIA-Lithium-disilicatepress-ceramic-92379.html.

10. Peumans M, Van Meerbeek B, Lambrechts P, Vanherle G. The 5-year clinical performance of direct composite additions to correct tooth form and position. I. Esthetic qualities. Clin Oral Investig. 1997 Feb;1(1):12-8.

11. Turgut S, Bagis B. Effect of resin cement and ceramic thickness on final color of laminate veneers: an in vitro study. J Prosthet Dent. 2013 Mar; 109(3):179-86.

12. Nosti J. "Thin is in" the art of minimal \& no prep veneer. J N J Dent Assoc. 2009; 80(4): 30-1.

13. O'Brien WJ, Kay KS, Boenke KM, Groh CL. Sources of color variation on firing porcelain. Dent Mater. $1991 \mathrm{Jul}$; $7(3): 170-3$

14. Hammad IA, Stein RS. A qualitative study for the bond and color of ceramometals. Part II. J Prosthet Dent. 1991 Feb; 65(2):169-79.

15. Seghi RR, Johnston WM, O’Brien WJ. Spectrophotometric analysis of color differences between porcelain systems. J Prosthet Dent. 1986 Jul; 56(1):35-40.

16. Jorgenson MW, Goodkind RJ. Spectrophotometric study of five porcelain shades relative to the dimensions of color, porcelain thickness, and repeated firings. J Prosthet Dent. 1979 Jul;42(1):96-105.

17. Raptis NV, Michalakis KX, Hirayama H. Optical behavior of current ceramic systems. Int J Periodontics Restorative Dent. 2006 Feb;26(1):31-41.

18. Dozic A, Kleverlaan CJ, Meegdes M, Zel JV, Feilzer AJ (2003) The influence of porcelain layer thickness on the final shade of ceramic restorations. J Prosthet Dent 90(6):563-570.

19. Li Q, Yu H, Wang YN. Spectrophotometric evaluation of the optical influence of core build-up composites on allceramic materials. Dent Mater. 2009 Feb;25(2):158-65.

20. Ledić K, Majnarić I, Milardović S, Ortolan, Špalj S, Štefančić S, Mehulić K. Analysis of Translucency Parameter of Glass-Ceramics Fabricated by Different Techniques. Acta Stomatol Croat. 2015 Mar;49(1):27-35.
21. Vichi A, Carrabba M, Paravina R, Ferrari M. Translucency of ceramic materials for CEREC CAD/CAM system. J Esthet Restor Dent. 2014 Jul-Aug;26(4):224-31.

22. Öztürk E, Chiang YC, Coşgun E, Bolay Ş, Hickel R, Ilie $\mathrm{N}$. Effect of resin shades on opacity of ceramic veneers and polymerization efficiency through ceramics. J Dent. 2013 Nov;41 Suppl 5:e8-14.

23. Archegas LR, Freire A, Vieira S, Caldas DB, Souza EM Colour stability and opacity of resin cements and flowable composites for ceramic veneer luting after accelerated ageing. J Dent. 2011 Nov;39(11):804-10

24. Pissaia JF, Correr GM, Gonzaga CC, Cunha LF. Influence of shade, curing mode, and aging on the color stability of resin cements. Braz J Oral Sci 2015; 14:272-5.

25. Uchida H, Vaidyanathan J, Viswanadhan T, Vaidyanathan TK. Color stability of dental composites as a function of shade. J Prosthet Dent. 1998 Apr;79(4):372-7.

26. Marchack BW, Sato S, Marchack CB, White SN. Complete and partial contour zirconia designs for crowns and fixed dental prostheses: a clinical report. J Prosthet Dent. 2011 Sep;106(3):145-52..

27. Liberato WF, Barreto IC, Costa PP, de Almeida CC, Pimentel W, Tiossi R. A comparison between visual, intraoral scanner, and spectrophotometer shade matching: A clinical study. J Prosthet Dent. 2019 Feb;121(2):271275.

28. CIE.Calorimetry: official recommendations of the International Commission on Illumination. Paris: Commission Internationale de l'Èclairage [International Commission on Illumination], 1976; CIE No. 15 (E-1.3.1).

29. Kandil BSM, Hamdy AM, Aboelfadl AK, El-Anwar MI. Effect of ceramic translucency and luting cement shade on the color masking ability of laminate veneers. Dent Res J (Isfahan). 2019 May-Jun; 16(3):193-199.

30. Knispel G. Factors affecting the process of color matching restorative materials to natural teeth. Quintessence Int. $1991 \mathrm{Jul} ; 22(7): 525-31$.

31. Çömlekoğlu ME, Paken G, Tan F, Dündar-Çömlekoğlu M, Özcan M, Akan E, Aladağ A. Evaluation of Different Thickness, Die Color, and Resin Cement Shade for Veneers of Multilayered CAD/CAM Blocks. J Prosthodont. 2016 Oct; 25(7):563-569.

32. . Barizon KT, Bergeron C, Vargas MA, Qian F, Cobb DS, Gratton DG, Geraldeli S. Ceramic materials for porcelain veneers: part II. Effect of material, shade, and thickness on translucency. J Prosthet Dent. 2014 Oct;112(4):864-70 
33. Oh SH, Kim SG. Effect of abutment shade, ceramic thickness, and coping type on the final shade of zirconia all-ceramic restorations: in vitro study of color masking ability. J Adv Prosthodont. 2015 Oct;7(5):368-74.

34. Zarone F, Ruggiero G, Leone R, Breschi L, Leuci S, Sorrentino R. Zirconia-Reinforced Lithium Silicate (ZLS) mechanical and biological properties: a literature review. J Dent. 2021 Apr 14:103661.

35. Li Y. Stain removal and whitening by baking soda dentifrice: A review of literature. J Am Dent Assoc. 2017 Nov; 148(11S):S20-S26.

36. ALGhazali N, Laukner J, Burnside G, Jarad FD, Smith PW, Preston AJ. An investigation into the effect of try-in pastes, uncured and cured resin cements on the overall color of ceramic veneer restorations: an in vitro study. J Dent. 2010; 38 Suppl 2:e78-86.

37. Nakamura T, Saito O, Fuyikawa J, Ishigaki S. Influence of abutment substrate and ceramic thickness on the colour of heat-pressed ceramic crowns. J Oral Rehabil. 2002; 29:805-9.

38. Shimada K, Nakazawa M, Kakehashi Y, Matsumura H Influence of abutment materials on the resultant color of heat-pressed lithium disilicate ceramics. Dent Mater J. 2006; 25:20-5.

39. Bagis B, Turgut S. Optical properties of current ceramics systems for laminate veneers. J Dent. 2013 Aug;41 Suppl 3:e24-30

40. Paravina RD, Ghinea R, Herrera LJ, Bona AD, Igiel C, Linninger M, Sakai M, Takahashi H, Tashkandi E, Perez Mdel M. Color difference thresholds in dentistry. J Esthet Restor Dent. 2015 Mar-Apr;27 Suppl 1:S1-9.

41. Al Ben Ali A, Kang K, Finkelman MD, Zandparsa R, Hirayama $\mathrm{H}$. The effect of variations in translucency and background on color differences in $\mathrm{CAD} / \mathrm{CAM}$ lithium disilicate glass ceramics. J Prosthodont. 2014 Apr;23(3):213-20.

42. Dozic A, Tsagkari M, Khashayar G, Aboushelib M. Color management of porcelain veneers: influence of dentin and resin cement colors. Quintessence Int. 2010 JulAug;41(7):567-73. PMID: 20614043.

43. Kürklü D, Azer SS, Yilmaz B, Johnston WM. Porcelain thickness and cement shade effects on the colour and translucency of porcelain veneering materials. J Dent. 2013 Nov;41(11):1043-50.

44. Ozturk O, Uludag B, Usumez A, Sahin V, Celik G. The effect of ceramic thickness and number of firings on the color of two all-ceramic systems. J Prosthet Dent. 2008 Aug;100(2):99-106

45. Pires LA, Novais PM, Araújo VD, Pegoraro LF. Effects of the type and thickness of ceramic, substrate, and cement on the optical color of a lithium disilicate ceramic. J Prosthet Dent. 2017 Jan;117(1):144-149.

46. Magne P, Versluis A, Douglas WH. Effect of luting composite shrinkage and thermal loads on the stress distribution in porcelain laminate veneers. J Prosthet Dent. 1999 Mar;81(3):335-44.

47. Dozic AKC, El-Zohairy A, Feilzer AJ, Khashayar G. Performance of five commercially available tooth color-measuring devices. J Prosthodont.2007; 16:93-100.

48. Brodbelt RH, O'Brien WJ, Fan PL. Translucency of dental porcelains. J Dent Res. 1980 Jan; 59(1):70-5.

49. Lee YK. Influence of scattering/absorption characteristics on the color of resin composites. Dent Mater. 2007 Jan;23(1):124-31.

50. Chaiyabutr Y, Kois JC, Lebeau D, Nunokawa G. Effect of abutment tooth color, cement color, and ceramic thickness on the resulting optical color of a $\mathrm{CAD} / \mathrm{CAM}$ glass-ceramic lithium disilicate-reinforced crown. J Prosthet Dent. 2011 Feb;105(2):83-90.

51. Vichi A, Ferrari M, Davidson CL. Influence of ceramic and cement thickness on the masking of various types of opaque posts. J Prosthet Dent. 2000 Apr;83(4):412-7.

52. Chang J, Da Silva JD, Sakai M, Kristiansen J, IshikawaNagai S. The optical effect of composite luting cement on all ceramic crowns. J Dent. 2009 Dec;37(12):937-43. doi: 10.1016/j.jdent.2009.07.009. Epub 2009 Aug 4. PMID: 19660518.

53. Al Hamad KQ, Obaidat II, Baba NZ. The Effect of Ceramic Type and Background Color on Shade Reproducibility of All-Ceramic Restorations. J Prosthodont. 2020 Jul;29(6):511-517.

54. Skyllouriotis AL, Yamamoto HL, Nathanson D. Masking properties of ceramics for veneer restorations. J Prosthet Dent. 2017 Oct; 118(4):517-523.

55. Antonson SA, Anusavice KJ. Contrast ratio of veneering and core ceramics as a function of thickness. Int J Prosthodont. 2001 Jul-Aug; 14(4):316-20. PMID: 11508085.

56. Ge J, Wang XZ, Feng HL. Influence of different post core materials on the color of Empress 2 full ceramic crowns. Chin Med J (Engl). 2006 Oct 20;119(20):1715-20.

57. Turgut S, Bagis B. Colour stability of laminate veneers: an in vitro study. J Dent. 2011 Dec;39 Suppl 3:e57-64. 
58. Park YJ, Chae KH, Rawls HR. Development of a new photoinitiation system for dental light-cure composite resins. Dent Mater. 1999 Mar;15(2):120-7.

59. Jung H, Friedl KH, Hiller KA, Haller A, Schmalz G. Curing efficiency of different polymerization methods through ceramic restorations. Clin Oral Investig. 2001 Sep; 5(3):156-61.

60. Czigola A, Abram E, Kovacs ZI, Marton K, Hermann
P, Borbely J. Effects of substrate, ceramic thickness, translucency, and cement shade on the color of CAD/ CAM lithium-disilicate crowns. J Esthet Restor Dent. 2019 Sep;31(5):457-464.

61. Perroni AP, Amaral C, Kaizer MR, Moraes RR, Boscato N. Shade of Resin-Based Luting Agents and Final Color of Porcelain Veneers. J Esthet Restor Dent. 2016 Sep;28(5):295-303. doi: 10.1111/jerd.12196. Epub 2016 Feb 15. PMID: 26876053 